\title{
Factors Associated with Positive Mental Health in a Portuguese Community Sample: A Look Through the Lens of Ryff's Psychological Well-Being Model
}

\author{
Helder Miguel Fernandes'1,2, José Vasconcelos-Raposo ${ }^{1,2}$ \\ and Robert Brustad ${ }^{3}$ \\ ${ }^{1}$ Research Centre in Sport, Health and Human Development, Vila Real \\ ${ }^{2}$ University of Trás-os-Montes and Alto Douro, Vila Real \\ ${ }^{3}$ University of Northern Colorado, Colorado \\ 1,2Portugal \\ ${ }^{3}$ USA
}

\section{Introduction}

Recent estimates of the extent of mental illness have revealed that about one in three individuals meet criteria for the diagnosis of at least one mental health disorder at some point of their lives (WHO International Consortium in Psychiatric Epidemiology, 2000). Studies have suggested that in any one-year time span at least one in five people is likely to be diagnosed with a mental disorder with anxiety and mood disorders (namely unipolar major depression) among the most commonly diagnosed disorders, with a lifetime prevalence of about $25 \%$ of the general population (Antony \& Swinson, 1996). In Portugal, chronic anxiety and depression tend to represent about $17 \%$ of the reasons why citizens undergo a long-term medical treatment (DG SANCO, 2007). Additionally, the first Portuguese mental health epidemiological study revealed that almost $23 \%$ of the individuals in the study reported a diagnosable mental illness during the previous year (Caldas de Almeida, 2010).

Although much is known about the correlates, prevalence and treatment of psychological disorders, still more remains unknown about the "positive side" of mental health. Some authors have argued that explicit efforts should be made toward the establishment of criteria for positive psychological health given its significance (Keyes, 2005; Ryff \& Singer, 1998; Seligman \& Csikszentmihalyi, 2000). Several developments and models have been presented since the seminal work of Marie Jahoda. Such formulations have become directed toward defining the core features/indicators of well-being, which have originated a myriad of different terminologies and theoretical and conceptual boundaries (i.e., well-being, happiness, positive affect and emotions, life satisfaction, and quality of life).

For this reason, the study of well-being has proliferated during the last decades, predominantly under the umbrella of the positive psychology movement (Seligman \& 
Csikszentmihalyi, 2000). Ryan and Deci's (2001) prominent review article suggested that the extensive body of well-being research could be restricted to two distinct, but related models, rooted in two ancient traditions, namely the hedonic and eudaimonic perspectives. The subjective well-being (SWB) model consists of three components: positive and negative affect, and life satisfaction (Diener et al., 1999). The second model, psychological well-being (PWB), is arguably best represented by Ryff's multidimensional structure of positive psychological functioning. This dual perspective has received some empirical support through factor analytic studies (Compton et al., 1996; Linley et al., 2009). Therefore, a considerable overlap should be recognized between the hedonic and eudaimonic perspectives, both in terms of theoretical and empirical aspects. Nevertheless, Carol Ryff has contributed to the discussion by identifying points of convergence in several mental health, clinical, and life span developmental theories and translating them to an empirical form of assessment (Ryff, 1989). These points of convergence constitute the core dimensions of the model, namely the importance of autonomy, environmental mastery, personal growth, positive relations with others, purpose in life, and self-acceptance. Therefore, these theoretically and empirically founded set of indicators appear to represent the core components of human flourishing.

The three components of subjective well-being have been extensively related with different types of variables. Meta-analytic evidence indicates that sociodemographic variables (gender, age and education) have a small effect on subjective well-being (Diener et al., 2003). Other variables, including self-reported health, religion and marriage have also been positively associated with positive affect and life satisfaction, although such influence is weak and its causal direction is unclear (see Diener et al., 1999). It has also been suggested that wealth might contribute to happiness and life satisfaction by providing certain basic needs but this relationship is more relevant in low-income countries (Diener, 2000). This premise was later supported by the meta-analysis performed by Howell and Howell (2008), which concluded that the effect size between economic status and subjective well-being was higher among low-income developing nations and for least educated samples than for more developed and higher income nations. Additionally, several personality traits have been found to be moderately correlated to life satisfaction, positive affect and negative affect (DeNeve \& Cooper, 1998). More recently, a study by Steel et al. (2008) indicated that the relationship between personality and SWB dimensions is higher (e.g., four times) than reported in previous meta-analyses. Other studies have also demonstrated that subjective well-being is positively related with self-esteem (especially in individualistic cultures), optimism and personal control (Diener \& Diener, 1995; Scheier et al., 2001). Moreover, previous research has demonstrated that people who adopt a healthy lifestyle (e.g., exercising enough, non-smoking, drinking moderately) are happier and more satisfied with their life (Grant et al., 2009; Shahab \& West, 2011), report lower levels of depression and anxiety (Mykletun et al., 2008; Rethorst et al., 2009; Wipfli et al., 2008), and have more favourable views about the self (Spence et al., 2005). These final psychosocial dimensions tend to be usually included under the umbrella of subjective well-being.

Compared with the hedonic perspective, the eudaimonic approach has been much less frequently studied, especially with large scale populations. Rare exceptions are the investigations directed by Carol Ryff, namely the MIDUS (Midlife in the United States)/MIDJA (Midlife in Japan), NSFH (National Survey of Families and Households), and WLS (Wisconsin Longitudinal Study). Previous empirical research has examined how 
eudaimonic well-being is influenced by sociodemographic factors, such as age, gender, socioeconomic status, race/ethnicity and culture. Aspects of well-being, such as positive relations and self-acceptance have consistently showed little age variation, while autonomy and environmental mastery have been found to be positively related to age. Moreover, cross-sectional data has shown evidence that purpose in life and personal growth decline across age periods (Ryff, 1989; Ryff \& Keyes, 1995). However, Springer et al. (2011) have recently suggested that longitudinal age variations explain a very small proportion of the variance across the PWB dimensions. In addition, few gender differences have been identified, with women generally rating themselves higher on positive relations and personal growth than men (Ryff, 1989; Ryff \& Keyes, 1995). With regard to socioeconomic status, available evidence has consistently demonstrated that educational attainment, occupational status and income are positive predictors of eudaimonic well-being (Keyes et al., 2002; Marmot et al., 1997; Ryff \& Singer, 1996). A further line of inquiry has also investigated how well-being is affected by different challenges in life (e.g., parenthood, giving care to an ill or disabled significant other, experiencing relocation, health changes on later life) as well as by the individual's interpretations of these experiences (Heidrich \& Ryff, 1993; Ryff \& Heidrich, 1997). Previous correlational and factor-analytic studies have also demonstrated that self-esteem shows highest associations with self-acceptance, purpose in life and environmental mastery (Compton, 2001; Paradise \& Kernis, 2002; Ryff, 1989). Eudaimonic well-being has also been linked with reduced biological risk, such as lower levels of daily salivary cortisol, pro-inflammatory cytokines, cardiovascular risk, and longer REM sleep duration (Lindfors \& Lundberg, 2002; Ryff et al., 2004) and left prefrontal cortex activation (Urry et al., 2004), which is associated better emotional outcomes (Davidson, 2004). Furthermore, the relation between health-promoting behaviours and psychological well-being has been less explored. The scarce available evidence suggests that exercisers score significantly higher than non-exercisers on all PWB dimensions, with the highest effect sizes being reported for purpose in life, positive relations and self-acceptance (Edwards et al., 2005). Gunnell (2009) also observed a positive relationship $(r=0.22)$ between a measure of eudaimonic well-being (Subjective Vitality Scale) and leisure-time physical activity in individuals with osteoporosis. Additionally, Besenski (2009) suggested that the relationship between health-enhancing physical activity and psychological well-being is best explained by the experience during the activity, rather than the level (duration, frequency, intensity) of activity. Specifically with adolescent samples, Vleioras and Bosma (2005) found that avoiding facing identity issues is negatively related to all psychological well-being dimensions. Additionally, Fernandes and Vasconcelos-Raposo (2008) demonstrated that psychological well-being, as measured by an adaptation of Ryff's scales (Fernandes et al., 2010), is related to specific sociodemographic (gender and age), socio-cultural (parent-child relationship, family structure and place of residence), and psychological variables (selfesteem, school satisfaction and social anxiety) during adolescence.

According to Ryff and Singer (1998), positive human health should be conceptualized as a multidimensional dynamic process that includes physical, socio-cultural and mental components. Moreover, these authors suggested that future research should identify and understand the factors associated with positive psychological functioning and develop positive health interventions based upon this knowledge. To the best of our knowledge, few studies have analyzed the relation between health-promoting behaviours (exercise, nonsmoking) and eudaimonic well-being (e.g., Besenski, 2009; Edwards et al., 2005; Kimiecik, 
2011). As such, the present research makes an original contribution to the literature by identifying and evaluating some of the possible sociodemographic, lifestyle and psychosocial correlates of psychological well-being in a non-American sample (Portugal).

Therefore, the present empirical study aims to examine the influence of sociodemographic (gender, age, place of residence, educational attainment, and socioeconomic status), lifestyle (smoking and physical activity) and psychosocial (body satisfaction) factors on positive mental health in a large Portuguese community sample. Taking into account the above considerations, the six dimensions of Ryff's well-being model were designated as indicators of positive mental health (Keyes, 2005; Ryff \& Singer, 1998), and were selected as the psychological outcomes to be studied.

\section{Method}

This study used a cross-sectional, descriptive, and correlational research design.

\subsection{Participants}

A sample of 783 individuals (355 men and 428 women) randomly recruited from the northern and central regions of Portugal participated in the study. The mean age of the sample was $34.45(\mathrm{SD}=11.77)$ years, with an age range from 18 to 78 years. Age was divided into three age groups: young adults $(\leq 29 \mathrm{yrs})$, midlife adults (30-54 yrs), and older adults $(\geq$ $55 \mathrm{yrs})$. As a result, 339 individuals were referred to as young adults (43.3\%), 403 were referred to as midlife adults (51.5\%), and 41 were considered older adults (5.2\%). A total of $358(45.7 \%)$ individuals reported living a rural area, while $425(54.3 \%)$ reported living in urban areas. Educational attainment was divided into three groups: 9 or fewer years of education $(n=324,41.4 \%) ; 12$ or fewer years of education $(n=253,32.3 \%)$; and academic degree $(n=206,26.3 \%)$. The mean for years of education was $9.25(S D=3.78)$. Regarding the sample's economic levels, $266(34.0 \%)$ reported receiving one minimum monthly salary (MMS; nearly €485), 349 (44.6\%) reported one to two MMS, 112 (14.3\%) reported more than two and three MMS, while the remaining 56 (7.2\%) individuals reported incomes higher than three MMS. The sample was divided in three socioeconomic status groups: low (1 MMS), moderate (1 to 2 MMS) and high (more than 2 MMS).

Data were collected using a street intercept survey method. All participants were informed of the study's goals and provided a signed informed consent.

\subsection{Instruments}

Initially, participants responded to a sociodemographic questionnaire. Educational attainment was assessed by the highest educational qualification achieved. The socioeconomic status (low, moderate or high) was measured by occupational level and monthly income. Body satisfaction was evaluated by one question ("How satisfied are you with your body/appearance?") using a 10-point response scale (1: very dissatisfied to 10: very satisfied). Smoking was assessed with a frequency item (number of cigarettes per day), while exercise measurement was based on a composite average of two single self-report items assessing the number of days individuals accumulated 30 or more minutes of moderate to vigorous physical activity during the past 7 days and for a typical week. Based 
on this form of screening measure, respondents were classified into one of three groups regarding levels of physical activity: inactive ( $<1$ day/week), insufficiently active $(\geq 1$ and $<$ 5 days/week) and active ( $\geq 5$ days/week). In relation to the recognized amount of physical activity needed to promote and maintain health, the American College of Sports Medicine (ACSM) and the American Heart Association (AHA) expert panel of scientists have recommended that "...healthy adults aged 18-65 yr need moderate-intensity aerobic physical activity for a minimum of 30 min on five days each week" (Haskell et al., 2007, p. 1083).

A Portuguese translation (Novo et al., 1997) of the 54-item version of the Scales of Psychological Well-being (Ryff, 1989) was used. Each dimension contains 9 items, positively or negatively worded with responses to a 5-point Likert scale (1: Strongly disagree to 5: Strongly agree). Negatively worded items were reversed before any subsequent analysis, allowing the calculation of a global score with possible scale values range from 9 to 45 . Reliability coefficients (Cronbach's alpha) ranged between 0.68 (environmental mastery) and 0.77 (autonomy). The internal consistency value was 0.95 for the total psychological wellbeing score.

\subsection{Statistical analysis}

Descriptive statistics of data were presented as mean (M), standard deviation (SD), range and relative frequency (\%), when appropriate. Skewness and kurtosis coefficients were computed for univariate normality analyses purposes, and all values were within \pm 1 . Multivariate analysis of variance (MANOVA) followed by one-way analysis of variance (ANOVA) were used to investigate differences between gender, place of residence, educational attainment, socioeconomic status, smoking status and physical activity levels (inactive, insufficiently active and active) on the well-being dimensions. Partial eta-squared $\left(\eta_{p}{ }^{2}\right)$ was reported as a measure of the effect size between groups according to the following rule of thumb: small $(>0.01)$, medium $(>0.06)$ and large $(>0.14)$. Associations between variables were calculated using the Pearson product-moment coefficient. Additionally, hierarchical regression analysis was used to determine the influence of different blocks of variables (sociodemographic, lifestyle and psychosocial) on the dependent variables. All of these statistical analyses were conducted using SPSS (version 16.0).

\section{Results}

\subsection{Descriptive and univariate normality analysis}

Table 1 shows descriptive statistics (range, means and standard deviations) and univariate normality measures (skewness and kurtosis) for the measured variables.

Results indicate moderate to high values of smoking frequency and body satisfaction, and low levels of self-reported physical activity (about two days a week). Mean values of the PWB dimensions ranged between 32.48 (self-acceptance) and 34.69 (personal growth) on a possible scale range of 9 to 45 . Absolute values of the univariate skewness and kurtosis were within the range of -1 to +1 , and were interpreted as normally distributed. For study purposes, subjects were also divided according to their smoking and physical activity status. Frequency distribution analysis revealed a $36.3 \%$ prevalence rate of smoking and a $37.3 \%$ prevalence rate of physical inactivity. Only $11.0 \%$ of the total sample reported achieving recommended physical activity levels (minimum of $30 \mathrm{~min}$ on five or more days each week). 


\begin{tabular}{lccccc}
\hline Variables & Range & $\mathrm{M}$ & $\mathrm{SD}$ & Skewness & Kurtosis \\
\hline Smoking (cigarettes per day) & $0-35$ & 14.57 & 9.54 & 0.98 & -0.77 \\
Physical activity (days per week) & $0-7$ & 1.77 & 1.94 & 0.95 & 0.37 \\
Body satisfaction & $1-10$ & 7.00 & 1.84 & -0.40 & 0.09 \\
Autonomy & $15-45$ & 33.63 & 4.94 & -0.44 & 0.45 \\
Environmental mastery & $15-45$ & 32.78 & 4.31 & -0.31 & 0.81 \\
Personal growth & $21-45$ & 34.69 & 4.54 & -0.26 & -0.14 \\
Positive relations & $16-45$ & 33.45 & 4.78 & -0.35 & 0.33 \\
Purpose in life & $12-45$ & 34.12 & 4.80 & -0.45 & 0.76 \\
Self-acceptance & $13-45$ & 32.48 & 4.64 & -0.52 & 0.96 \\
Total PWB score & $93-256$ & 201.15 & 21.78 & -0.43 & 0.91 \\
\hline
\end{tabular}

Table 1. Descriptive and univariate normality analysis.

\subsection{Comparative analysis}

A MANOVA was conducted to compare the effect of gender on the six dimensions of psychological well-being. Results are summarized in Table 2.

\begin{tabular}{lccccc}
\hline Variables & $\begin{array}{c}\text { Males } \\
\mathrm{M} \pm \mathrm{SD}\end{array}$ & $\begin{array}{c}\text { Females } \\
\mathrm{M} \pm \mathrm{SD}\end{array}$ & $F$ & $p$ & $\eta_{\mathrm{p}}{ }^{2}$ \\
\hline Autonomy & $33.64 \pm 4.64$ & $33.62 \pm 5.18$ & 0.01 & 0.943 & 0.00 \\
Environmental mastery & $33.35 \pm 4.33$ & $32.30 \pm 4.23$ & 11.60 & 0.001 & 0.02 \\
Personal growth & $34.57 \pm 4.29$ & $34.79 \pm 4.75$ & 0.46 & 0.500 & 0.00 \\
Positive relations & $33.49 \pm 4.71$ & $33.42 \pm 4.84$ & 0.05 & 0.822 & 0.00 \\
Purpose in life & $34.24 \pm 4.70$ & $34.01 \pm 4.88$ & 0.46 & 0.499 & 0.00 \\
Self-acceptance & $32.96 \pm 4.10$ & $32.09 \pm 5.02$ & 6.89 & 0.009 & 0.01 \\
Total PWB score & $202.26 \pm 20.26$ & $200.23 \pm 22.94$ & 1.69 & 0.194 & 0.00 \\
\hline
\end{tabular}

Table 2. Means (M), standard deviations (SD) and univariate effects of the psychological well-being dimensions by gender.

A significant multivariate effect of gender was found $\left(F_{(6,776)}=3.93, p=0.001\right.$, Wilk's $\left.\lambda=0.97\right)$, although the eta value suggests a small effect $\left(\eta_{p^{2}}=0.03\right)$. Simple main effects analysis showed that males reported higher levels of environmental mastery and self-acceptance $(p<$ $0.010)$. Moreover, a one-way ANOVA produced no significant differences in the total score $(p=0.194)$.

In order to identify possible gender differences by age groups, three independent MANOVAs were conducted for young, midlife and older adults. A significant effect was only found for young adults $\left(F_{(6,332)}=3.17, p=0.005\right.$, Wilk's $\left.\lambda=0.95, \eta_{p}{ }^{2}=0.06\right)$, indicating that the previous gender differences were only evident during this younger age period.

Table 3 presents the comparative analysis between age groups.

A one-way MANOVA was used to examine the association between age groups and wellbeing scores, revealing an overall main effect for age groups $\left(F_{(12,1550)}=4.54, p=0.000\right.$, Wilk's $\lambda=0.93)$, but a small effect size $\left(\eta_{\mathrm{p}}{ }^{2}=0.04\right)$. Follow-up univariate analyses indicated significant differences in four of the six dependent variables. Post hoc comparisons using Scheffé's test indicated that young adults reported higher scores of personal growth $(p=$ 
Factors Associated with Positive Mental Health in a Portuguese

\begin{tabular}{lcccccc}
\hline Variables & $\begin{array}{c}\text { Young adults } \\
\mathrm{M} \pm \mathrm{SD}\end{array}$ & $\begin{array}{c}\text { Midlife adults } \\
\mathrm{M} \pm \mathrm{SD}\end{array}$ & $\begin{array}{c}\text { Older adults } \\
\mathrm{M} \pm \mathrm{SD}\end{array}$ & $F$ & $p$ & $\eta_{\mathrm{p}}{ }^{2}$ \\
\hline Autonomy & $34.09 \pm 4.97$ & $33.48 \pm 4.77$ & $31.22 \pm 5.65$ & 6.63 & 0.001 & 0.02 \\
Environmental mastery & $32.81 \pm 4.38$ & $32.67 \pm 4.20$ & $33.56 \pm 4.71$ & 0.82 & 0.440 & 0.00 \\
Personal growth & $35.48 \pm 4.39$ & $34.27 \pm 4.49$ & $32.34 \pm 5.08$ & 12.65 & 0.000 & 0.03 \\
Positive relations & $34.09 \pm 4.61$ & $32.94 \pm 4.79$ & $33.17 \pm 5.46$ & 5.48 & 0.004 & 0.01 \\
Purpose in life & $34.65 \pm 4.89$ & $32.94 \pm 4.79$ & $33.17 \pm 5.45$ & 3.91 & 0.021 & 0.01 \\
Self-acceptance & $32.88 \pm 4.87$ & $32.17 \pm 4.41$ & $32.29 \pm 4.80$ & 2.15 & 0.117 & 0.00 \\
Total PWB score & $204.00 \pm 22.01$ & $199.29 \pm 20.93$ & $195.83 \pm 25.27$ & 5.66 & 0.004 & 0.02 \\
\hline
\end{tabular}

Table 3. Means (M), standard deviations (SD) and univariate effects of the psychological well-being dimensions by age groups.

$0.001)$, positive relations $(p=0.005)$ and purpose in life $(p=0.042)$ than midlife adults, and higher levels of autonomy $(p=0.002)$ and personal growth $(p=0.000)$ than older adults. In addition, a decrement in autonomy scores was also observed between midlife and older adults $(p=0.019)$. A one-way ANOVA revealed a small detrimental effect as age groups increased on the total PWB score $(p=0.004)$.

The results of the psychological well-being scales comparison by place of residence are summarized in Table 4.

\begin{tabular}{lccccc}
\hline Variables & $\begin{array}{c}\text { Rural } \\
\mathrm{M} \pm \mathrm{SD}\end{array}$ & $\begin{array}{c}\text { Urban } \\
\mathrm{M} \pm \mathrm{SD}\end{array}$ & $F$ & $p$ & $\eta_{\mathrm{p}}{ }^{2}$ \\
\hline Autonomy & $33.16 \pm 4.98$ & $34.03 \pm 4.88$ & 6.05 & 0.014 & 0.01 \\
Environmental mastery & $32.67 \pm 4.20$ & $32.87 \pm 4.39$ & 0.45 & 0.501 & 0.00 \\
Personal growth & $33.98 \pm 4.68$ & $35.29 \pm 4.34$ & 16.37 & 0.000 & 0.02 \\
Positive relations & $33.13 \pm 4.71$ & $33.73 \pm 4.83$ & 3.06 & 0.081 & 0.00 \\
Purpose in life & $33.86 \pm 4.62$ & $34.33 \pm 4.94$ & 1.82 & 0.178 & 0.00 \\
Self-acceptance & $32.22 \pm 4.63$ & $32.71 \pm 4.64$ & 2.13 & 0.145 & 0.00 \\
Total PWB score & $199.01 \pm 21.70$ & $202.95 \pm 21.77$ & 6.38 & 0.012 & 0.01 \\
\hline
\end{tabular}

Table 4. Means (M), standard deviations (SD) and univariate effects of the psychological well-being dimensions by place of residence.

A significant multivariate effect of place of residence was found for the six dependent variables $\left(F_{(6,776)}=3.36, p=0.003\right.$, Wilk's $\left.\lambda=0.98\right)$, although the eta value was small $\left(\eta_{\mathrm{p}}{ }^{2}=\right.$ 0.03). Subsequent univariate analysis showed significant differences only in two dimensions, with urban residents reporting higher scores of autonomy and personal growth. A one-way ANOVA showed that rural residents revealed lower scores of the total PWB score $(p=0.012)$.

Next, a MANOVA was conducted to compare the effect of educational attainment on the six dimensions of psychological well-being. Results are summarized in Table 5.

A significant multivariate effect of educational attainment was found $\left(F_{(12,1550)}=11.24, p=\right.$ 0.000 , Wilk's $\lambda=0.85)$, with the eta value suggesting a moderate effect $\left(\eta_{p}{ }^{2}=0.08\right)$. Simple main effects analysis showed that higher educational attainment (10 or more years of schooling completed) was associated with higher scores on all of the psychological wellbeing dimensions, when compared with the less educated group ( $\leq 9$ years). A large effect 


\begin{tabular}{lcccccc}
\hline Variables & $\begin{array}{c}\leq 9 \text { years } \\
\mathrm{M} \pm \mathrm{SD}\end{array}$ & $\begin{array}{c}\leq 12 \text { years } \\
\mathrm{M} \pm \mathrm{SD}\end{array}$ & $\begin{array}{c}\text { Academic } \\
\mathrm{M} \pm \mathrm{SD}\end{array}$ & $F$ & $p$ & $\eta_{\mathrm{p}}{ }^{2}$ \\
\hline Autonomy & $32.51 \pm 5.12$ & $34.43 \pm 4.82$ & $34.41 \pm 4.46$ & 14.75 & 0.000 & 0.04 \\
Environmental mastery & $31.94 \pm 4.53$ & $33.26 \pm 4.34$ & $33.51 \pm 3.64$ & 10.89 & 0.000 & 0.03 \\
Personal growth & $32.61 \pm 4.42$ & $36.08 \pm 4.19$ & $36.27 \pm 3.83$ & 68.01 & 0.000 & 0.15 \\
Positive relations & $32.24 \pm 4.64$ & $34.32 \pm 4.76$ & $34.29 \pm 4.62$ & 18.61 & 0.000 & 0.05 \\
Purpose in life & $32.69 \pm 4.55$ & $34.99 \pm 4.93$ & $35.29 \pm 4.44$ & 26.26 & 0.000 & 0.06 \\
Self-acceptance & $31.43 \pm 4.43$ & $33.02 \pm 5.06$ & $33.50 \pm 4.08$ & 15.62 & 0.000 & 0.04 \\
Total PWB score & $193.41 \pm 21.29$ & $206.09 \pm 21.54$ & $207.25 \pm 19.02$ & 38.46 & 0.000 & 0.09 \\
\hline
\end{tabular}

Table 5. Means (M), standard deviations (SD) and univariate effects of the psychological well-being dimensions by educational attainment.

size was found for personal growth $\left(\eta_{\mathrm{p}}{ }^{2}=0.15\right)$. As expected, a moderate incremental effect of educational attainment on the total PWB score was also observed $\left(\eta_{\mathrm{p}}{ }^{2}=0.09\right)$.

Table 6 presents the comparative analysis between socioeconomic status groups.

\begin{tabular}{lcccccc}
\hline Variables & $\begin{array}{c}\text { Low } \\
\mathrm{M} \pm \mathrm{SD}\end{array}$ & $\begin{array}{c}\text { Moderate } \\
\mathrm{M} \pm \mathrm{SD}\end{array}$ & $\begin{array}{c}\text { High } \\
\mathrm{M} \pm \mathrm{SD}\end{array}$ & $F$ & $p$ & $\eta_{\mathrm{p}}{ }^{2}$ \\
\hline Autonomy & $32.97 \pm 5.40$ & $34.00 \pm 4.65$ & $33.91 \pm 4.69$ & 3.66 & 0.026 & 0.01 \\
Environmental mastery & $31.52 \pm 4.67$ & $33.12 \pm 4.04$ & $34.07 \pm 3.71$ & 21.00 & 0.000 & 0.05 \\
Personal growth & $33.97 \pm 5.07$ & $34.71 \pm 4.24$ & $35.82 \pm 4.03$ & 8.70 & 0.000 & 0.02 \\
Positive relations & $32.77 \pm 4.93$ & $33.70 \pm 4.64$ & $34.01 \pm 4.73$ & 4.30 & 0.014 & 0.01 \\
Purpose in life & $32.85 \pm 5.26$ & $34.44 \pm 4.37$ & $35.43 \pm 4.42$ & 17.11 & 0.000 & 0.04 \\
Self-acceptance & $31.37 \pm 5.29$ & $32.81 \pm 4.16$ & $33.58 \pm 4.14$ & 13.16 & 0.000 & 0.03 \\
Total PWB score & $195.44 \pm 24.52$ & $202.77 \pm 19.75$ & $206.80 \pm 19.07$ & 16.39 & 0.000 & 0.04 \\
\hline
\end{tabular}

Table 6. Means (M), standard deviations (SD) and univariate effects of the psychological well-being dimensions by socioeconomic status.

A one-way MANOVA was used to examine the association between socioeconomic status and well-being scores, revealing a small effect $\left(F_{(12,1550)}=5.20, p=0.000\right.$, Wilk's $\lambda=0.92, \eta_{p}{ }^{2}=$ 0.04). Follow-up univariate analyses indicated significant differences in all dependent variables. Post hoc comparisons using Scheffé's test indicated that groups with higher levels of socioeconomic status reported higher scores of well-being, when compared with the lowest income group. A one-way ANOVA showed that the group with lower socioeconomic status revealed lower scores of the total PWB score $(p=0.000)$.

The results of the psychological well-being scales comparison by smoking status are summarized in Table 7. A one-way MANOVA was used to examine the association between smoking status and well-being scores, revealing an overall main effect for nonsmoking/smoking groups $\left(F_{(6,776)}=7.44, p=0.000\right.$, Wilk's $\left.\lambda=0.95\right)$, but with a small to medium effect size $\left(\eta_{\mathrm{p}}{ }^{2}=0.06\right)$. Follow-up univariate analyses only indicated significant differences for two of the six dependent variables, with non-smokers reporting higher scores of environmental mastery and purpose in life $(p<0.001)$. Additionally, a one-way ANOVA by smoking status produced no significant differences in the total score $(p=0.143)$.

Lastly, a MANOVA was conducted to compare the effect of physical activity on the psychological well-being dimensions. Results are summarized in Table 8. 


\begin{tabular}{lccccc}
\hline Variables & $\begin{array}{c}\text { Non-smokers } \\
\mathrm{M} \pm \mathrm{SD}\end{array}$ & $\begin{array}{c}\text { Smokers } \\
\mathrm{M} \pm \mathrm{SD}\end{array}$ & $F$ & $p$ & $\eta_{\mathrm{p}}{ }^{2}$ \\
\hline Autonomy & $33.57 \pm 4.74$ & $33.74 \pm 5.29$ & 0.21 & 0.646 & 0.00 \\
Environmental mastery & $33.20 \pm 3.92$ & $32.03 \pm 4.83$ & 13.74 & 0.000 & 0.02 \\
Personal growth & $34.80 \pm 4.43$ & $34.50 \pm 4.73$ & 0.83 & 0.364 & 0.00 \\
Positive relations & $33.36 \pm 4.63$ & $33.61 \pm 5.03$ & 0.47 & 0.494 & 0.00 \\
Purpose in life & $34.57 \pm 4.27$ & $33.32 \pm 5.52$ & 12.29 & 0.000 & 0.02 \\
Self-acceptance & $32.51 \pm 4.40$ & $32.45 \pm 5.05$ & 0.03 & 0.867 & 0.00 \\
Total PWB score & $202.01 \pm 19.91$ & $199.64 \pm 24.67$ & 2.15 & 0.143 & 0.00 \\
\hline
\end{tabular}

Table 7. Means (M), standard deviations (SD) and univariate effects of the psychological well-being dimensions by smoking status.

\begin{tabular}{lcccccc}
\hline Variables & $\begin{array}{c}\text { Inactive } \\
\mathrm{M} \pm \mathrm{SD}\end{array}$ & $\begin{array}{c}\text { Insuf. active } \\
\mathrm{M} \pm \mathrm{SD}\end{array}$ & $\begin{array}{c}\text { Active } \\
\mathrm{M} \pm \mathrm{SD}\end{array}$ & $F$ & $p$ & $\eta_{\mathrm{p}}{ }^{2}$ \\
\hline Autonomy & $33.23 \pm 4.92$ & $33.76 \pm 4.93$ & $34.37 \pm 4.99$ & 2.05 & 0.130 & 0.01 \\
Environmental mastery & $32.19 \pm 4.00$ & $32.99 \pm 4.37$ & $33.78 \pm 4.74$ & 5.67 & 0.004 & 0.02 \\
Personal growth & $33.91 \pm 4.78$ & $35.06 \pm 4.32$ & $35.62 \pm 4.41$ & 7.60 & 0.001 & 0.02 \\
Positive relations & $32.78 \pm 4.62$ & $33.70 \pm 4.76$ & $34.58 \pm 5.12$ & 5.91 & 0.003 & 0.02 \\
Purpose in life & $33.81 \pm 4.81$ & $34.31 \pm 4.73$ & $34.22 \pm 5.07$ & 0.94 & 0.390 & 0.00 \\
Self-acceptance & $32.19 \pm 4.51$ & $32.58 \pm 4.72$ & $33.06 \pm 4.70$ & 1.33 & 0.265 & 0.00 \\
Total PWB score & $198.10 \pm 21.30$ & $202.39 \pm 21.66$ & $205.63 \pm 22.74$ & 5.40 & 0.005 & 0.02 \\
\hline
\end{tabular}

Table 8. Means (M), standard deviations (SD) and univariate effects of the psychological well-being dimensions by physical activity status.

Results indicated a significant, albeit small $\left(\eta_{\mathrm{p}}{ }^{2}=0.02\right)$, multivariate effect of physical activity $\left(F_{(12,1550)}=2.67, p=0.001\right.$, Wilk's $\left.\lambda=0.96\right)$. Simple main effects analysis indicated significant differences in three of the six dependent variables. Post hoc comparisons using Scheffé's test indicated that active individuals reported higher scores of environmental mastery $(p=0.010)$ and positive relations $(p=0.009)$ than inactive adults. Moreover, physical activity groups (insufficiently active and active) reported higher personal growth scores than the inactive group $(p<0.01)$. A one-way ANOVA showed that the inactive group reported lower scores of the total PWB score $(p<0.01)$.

\subsection{Correlation and regression analysis}

Pearson correlation analysis were conducted to examine possible associations between sociodemographic (age, educational attainment, and socioeconomic status), lifestyle (smoking and physical activity), psychosocial (body satisfaction) factors and psychological well-being. Table 9 presents the bivariate correlations between these measures.

With regard to age, significant negative associations were found for autonomy, personal growth, positive relations with others and the total well-being score. Educational attainment and socioeconomic status were positively related with all well-being dimensions, with higher effects for personal growth. Body satisfaction was also positively correlated with all psychological well-being measures, with the highest association being with self-acceptance. Smoking frequency was negatively related with environmental mastery and purpose in life, 
while physical activity was positively correlated with environmental mastery, personal growth, positive relations with others, purpose in life and the total well-being score.

\begin{tabular}{lccccccc}
\hline Variables & AUT & EM & PG & PR & PL & SA & PWB \\
\hline Age & $-0.11^{* *}$ & 0.01 & $-0.23^{* *}$ & $-0.12^{* *}$ & $-0.11^{* *}$ & -0.06 & $-0.13^{* *}$ \\
Educational attainment (years) & $0.21^{* *}$ & $0.17^{* *}$ & $0.39^{* *}$ & $0.23^{* *}$ & $0.24^{* *}$ & $0.20^{* *}$ & $0.31^{* *}$ \\
Socioeconomic status & $0.16^{* *}$ & $0.24^{* *}$ & $0.32^{* *}$ & $0.20^{* *}$ & $0.27^{* *}$ & $0.23^{* *}$ & $0.30^{* *}$ \\
Smoking (cigarettes per day) & 0.03 & $-0.15^{* *}$ & -0.03 & 0.01 & $-0.13^{* *}$ & 0.02 & -0.06 \\
Physical activity (days per week) & 0.04 & $0.15^{* *}$ & $0.12^{* *}$ & $0.15^{* *}$ & 0.01 & 0.04 & $0.12^{* *}$ \\
Body satisfaction & $0.15^{* *}$ & $0.25^{* *}$ & $0.14^{* *}$ & $0.19^{* *}$ & $0.16^{* *}$ & $0.31^{* *}$ & $0.25^{* *}$ \\
\hline
\end{tabular}

Note: AUT - Autonomy; EM - Environmental mastery; PG - Personal growth; PR - Positive relations; PL - Purpose in life; SA - Self-acceptance; PWB - Total PWB score. ${ }^{*} p<0.05 ;{ }^{* *} p<0.01$

Table 9. Correlations between sociodemographic, lifestyle and psychosocial factors, and measures of psychological well-being.

Additionally, significant negative associations were found between age and educational attainment $(r=-0.29, p<0.001)$, and between smoking and physical activity $(r=-0.12, p<$ 0.01). As expected, a high correlation was observed between educational attainment and socioeconomic status $(r=0.81, p<0.001)$. Body satisfaction was equally related with educational attainment and socioeconomic status $\left(r_{\mathrm{s}}=0.11, p<0.01\right)$, and a positive relationship was also observed with physical activity $(r=0.15, p<0.001)$.

In order to determine the proportion of variance explained by each variable/factor (predictor), independent hierarchical regressions were conducted on each psychological well-being dimension (criterion). The first block of variables included the sociodemographic factors (gender: $1=$ male, $2=$ female; age; place of residence: $1=$ rural, $2=$ urban; educational attainment; and socioeconomic status). The second block included the two measured lifestyle factors (smoking and physical activity). Lastly, the third block was constituted by the only psychosocial variable (body satisfaction). The results of the sequential analyses are summarized in Table 10. For clarity purposes only the significant relationships are reported.

\begin{tabular}{|c|c|c|c|}
\hline Criterion and predictor & $\beta$ & $R^{2}$ & $\Delta R^{2}$ \\
\hline \multicolumn{4}{|l|}{ Autonomy } \\
\hline Block 1 & & 0.05 & - \\
\hline Educational attainment & $0.15^{*}$ & & \\
\hline Block 2 & & 0.05 & 0.00 \\
\hline Block 3 & & 0.07 & 0.02 \\
\hline Body satisfaction & $0.13^{* *}$ & & \\
\hline \multicolumn{4}{|l|}{ Environmental mastery } \\
\hline Block 1 & & 0.07 & - \\
\hline Gender & $-0.07^{*}$ & & \\
\hline Socioeconomic status & $0.27^{* *}$ & & \\
\hline Block 2 & & 0.10 & 0.03 \\
\hline Smoking & $-0.14^{\star *}$ & & \\
\hline Physical activity & $0.07^{*}$ & & \\
\hline Block 3 & & 0.14 & 0.04 \\
\hline Body satisfaction & $0.21^{* *}$ & & \\
\hline
\end{tabular}

Table 10. Summary of hierarchical regression analysis for predictors of psychological wellbeing dimensions. 


\begin{tabular}{|c|c|c|c|}
\hline Criterion and predictor & $\beta$ & $R^{2}$ & $\Delta R^{2}$ \\
\hline \multicolumn{4}{|l|}{ Personal growth } \\
\hline Block 1 & & 0.18 & - \\
\hline Age & $-0.17^{* *}$ & & \\
\hline Place of residence & $0.08^{*}$ & & \\
\hline Educational attainment & $0.22^{* *}$ & & \\
\hline Socioeconomic status & $0.13^{*}$ & & \\
\hline Block 2 & & 0.19 & 0.01 \\
\hline Physical activity & $0.08^{*}$ & & \\
\hline Block 3 & & 0.20 & 0.01 \\
\hline Body satisfaction & $0.09^{*}$ & & \\
\hline \multicolumn{4}{|l|}{ Positive relations } \\
\hline Block 1 & & 0.06 & - \\
\hline Age & $-0.09 *$ & & \\
\hline Educational attainment & $0.12^{*}$ & & \\
\hline Block 2 & & 0.08 & 0.02 \\
\hline Physical activity & $0.11^{* *}$ & & \\
\hline Block 3 & & 0.10 & 0.02 \\
\hline Body satisfaction & $0.15^{* *}$ & & \\
\hline \multicolumn{4}{|l|}{ Purpose in life } \\
\hline Block 1 & & 0.08 & - \\
\hline Age & $-0.12^{* *}$ & & \\
\hline Socioeconomic status & $0.26^{* *}$ & & \\
\hline Block 2 & & 0.10 & 0.02 \\
\hline Smoking & $-0.14^{* *}$ & & \\
\hline Block 3 & & 0.12 & 0.02 \\
\hline Body satisfaction & $0.13^{* *}$ & & \\
\hline \multicolumn{4}{|l|}{ Self-acceptance } \\
\hline Block 1 & & 0.07 & - \\
\hline Socioeconomic status & $0.21^{* *}$ & & \\
\hline Block 2 & & 0.07 & 0.00 \\
\hline Block 3 & & 0.14 & 0.07 \\
\hline Body satisfaction & $0.28 * *$ & & \\
\hline \multicolumn{4}{|l|}{ Total PWB score } \\
\hline Block 1 & & 0.12 & - \\
\hline Age & $-0.11^{* *}$ & & \\
\hline Socioeconomic status & $0.21^{* *}$ & & \\
\hline Block 2 & & 0.14 & 0.02 \\
\hline Physical activity & $0.10^{*}$ & & \\
\hline Block 3 & & 0.18 & 0.04 \\
\hline Body satisfaction & $0.21^{* *}$ & & \\
\hline
\end{tabular}

Note: ${ }^{*} p<0.05 ;{ }^{* *} p<0.01$

Table 10. Summary of hierarchical regression analysis for predictors of psychological wellbeing dimensions (continued). 
Results of the regression analyses demonstrated that sociodemographic variables explained $5 \%$ (autonomy) to $18 \%$ (personal growth) of the variance in the well-being dimensions. Within these block of variables, socioeconomic status followed by age and educational attainment were the most important predictors of the psychological well-being measures. The inclusion of lifestyle factors explained a small additional amount of variance (between $0 \%$ and 3\%) in the outcome dimensions. After controlling for the effects of the two first blocks, body satisfaction predicted $1 \%$ (personal growth) to $7 \%$ (self-acceptance) of additional variance in the criterion variables.

\section{Discussion}

The present cross-sectional research study aimed to extend knowledge on the positive mental health of Portuguese people by (1) using a multidimensional model of psychological well-being (Ryff, 1989), (2) studying a large non-American community sample and therefore extending previous findings, and (3) identifying the influence of specific sociodemographic, lifestyle and psychosocial factors on various well-being dimensions.

\subsection{The effects of sociodemographic factors}

By examining comparative and correlational analyses, it was possible to identify the multivariate and univariate effects of sociodemographic data (gender, age, place of residence, educational attainment, and socioeconomic status) on the explained well-being variance.

Previous empirical evidence has shown that women rate themselves higher on positive relations and personal growth than men (Ryff, 1989; Ryff \& Keyes, 1995). However, in the present study, males reported higher levels of environmental mastery and self-acceptance, but these differences were only observed during the young adulthood age range. A possible explanation for our findings might rely on the extensive body of research that has repeatedly found a higher incidence of certain psychological problems among women, such as depression and anxiety (WHO, 2004). Several explanations have been suggested in order to elucidate such sex differences, namely: the typical roles that women assume in the family, at home and in work settings (Almeida \& Kessler, 1998); the greater frequency of childhood and adulthood trauma reported by females (Nurullah, 2010); the differentiated manner of responding to stressful situations (Hankin \& Abramson, 2001); and potential biological determinants (Fitzgerald \& Dinan, 2010) among others. On one hand, our results suggest that, during this life transition between adolescence and midlife adulthood, males report a stronger sense of mastery, control and competence in managing the surrounding context and possess a more positive attitude towards the past and present self, including favourable and unfavourable qualities. On the other hand, there is also evidence to suggest that women are able to overcome responsibilities and adversities of emerging adulthood, since no other gender differences were observed in the following age periods.

The analysis of age effects on eudaimonic well-being showed a declining pattern in strength of autonomy, personal growth, positive relations, purpose in life and total well-being score across groups. Compared with previous cross-sectional data, our results provide mixed conclusions regarding meaningful trajectories of eudaimonic well-being across the life course. Findings from Carol Ryff's initial studies (Ryff, 1989; Ryff \& Keyes, 1995) suggested 
age increments for environmental mastery and autonomy, and a declining pattern for purpose in life and personal growth. More recently, Springer et al. (2011) investigated longitudinal age variations in the six well-being dimensions. Although age trends were not consistent between samples (WLS and MIDUS) and small proportions of variance were explained by age, it was possible to examine declining scores for autonomy (in WLS waves), personal growth, purpose in life and self-acceptance (in WLS waves). Thus, our findings support the assumption that experiences/opportunities for autonomy, personal growth, positive relations and purpose in life may be limited for cohorts of older persons or that these age groups place less value to these psychosocial dimensions when compared with the younger cohorts (or their past life). Obviously, future longitudinal research with populationbased surveys is needed in order to better understand how the aging process affects the positive mental health of the Portuguese people.

Regarding the effects of the place of residence, differences were found for autonomy, personal growth and total well-being scores across rural and urban groups. Given the scarce body of literature on this subject, such results need to be interpreted with caution, without neglecting the possible indirect effects of variables such as educational attainment, occupational status, income, access to health services, among others. Several studies have identified rural-urban disparities in psychiatric disorders and quality of life (Peen et al., 2007, 2010). Among a Portuguese adolescent sample, Fernandes and Vasconcelos-Raposo (2008) found that urban residents reported higher scores for personal growth, purpose in life, self-acceptance and total well-being. In a more general sense, it is possible to suggest that this results from the discrepancy between the aspirations and expectations of the individual and their ability to satisfy them within his environment/place of residence (Wilkening \& McGranahan, 1978). As such, our results suggest that urban residents are more self-determining and independent, more able to regulate social pressures to think and act in certain ways, less concerned with the evaluations and expectations of (significant) others, more open to new experiences and have a higher sense of continued development (realizing his/her potential). A possible explanation for this assumption is the higher levels of educational attainment $\left(F_{(1,781)}=40.50, p=0.000, \eta_{\mathrm{p}}{ }^{2}=0.05\right)$ and socioeconomic status $\left(F_{(1,781)}=48.47, p=0.000, \eta_{\mathrm{p}}{ }^{2}=0.06\right)$ reported by our urban sample group, which we analyse next.

Educational attainment and socioeconomic status were positively associated with all the psychological well-being dimensions, and were the sociodemographic variables that explained the greatest proportion of variance. These findings are consistent with previous cross-sectional empirical research (Keyes et al., 2002; Marmot et al., 1997; Ryff \& Singer, 1996), which has identified these factors as positive predictors of eudaimonic well-being. For example, Ryff (1989) revealed that self-rated finances was a leading predictor variable, especially for self-acceptance, environmental mastery, purpose in life and personal growth $\left(R^{2} \geq 13 \%\right)$. Therefore, this correlational evidence supports the assumption that a lower position in the social order not only increases the likelihood of negative health outcomes but that it also decreases the chances of psychological well-being (Ryff et al., 1999). Furthermore, Kaplan et al. (2008) examined the cumulative impact of different income measures in five of the six scales of psychological well-being. A longitudinal analysis showed a consistent increase of purpose in life, self-acceptance, personal growth and environmental mastery as mean income increased over the last three decades. These results emphasize the primary 
influence of economic well-being on psychological well-being and reflect the accumulation of socioeconomic advantage/disadvantage on eudaimonic well-being, throughout the adult life course. Therefore, if adults face significant challenges in their efforts and abilities to maintain a sense of purpose, self-realization and personal development, it is not surprising that a better socioeconomic condition affords important mediated or direct preventive and protective mechanisms in the face of stress, challenge, adversity and risk of disease. Thus, our results suggest that social class inequalities in education and income should represent important issues for public policies and intervention programs that aim to develop the positive mental health of the Portuguese population.

\subsection{The effects of lifestyle factors}

When testing the effects of lifestyle factors (smoking and exercising) on eudaimonic wellbeing, results from the comparative and correlational analyses indicated that these variables had a small effect ( $0 \%$ to $3 \%$ of the explained variance). Cigarette smoking was negatively associated with environmental mastery and purpose in life, while physical activity was positively correlated with environmental mastery, personal growth, positive relations and total well-being score.

Available empirical evidence has demonstrated that smoking affects not only a person's physical health (USDHHS, 2004), but also his mental health and well-being (Lawrence et al., 2009). In addition, review articles have indicated that smoking is more prevalent in people with mental health problems (e.g., Campion et al., 2008; Scott \& Happell, 2011). Physical activity, in turn, has been also associated with higher levels of happiness, life satisfaction and self-esteem (Grant et al., 2009; Shahab \& West, 2011; Spence et al., 2005), and with lower levels of depression and anxiety (Mykletun et al., 2008; Rethorst et al., 2009; Wipfli et al., 2008). The literature linking physical (in)activity and mental health is extensive, but for some reason, researchers have neglected the study of eudaimonic well-being. The effects of physical activity on one's mental well-being have been mainly interpreted by reducing anxiety, stress and depression, or through mood, self-esteem and quality of life enhancement. However, leading a life of purpose, having quality connections to others and experiencing continued growth are unique facets of eudaimonic well-being and distinct from indicators of subjective well-being (Ryff \& Singer, 1998). Such a premise is supported by our results, in which, higher levels of environmental mastery, personal growth and positive relations were reported by physically active individuals, especially those who met the ACSM/AHA recommendations. Previous research with a sample of Portuguese older adults (60-95 years) also found a positive association between physical activity levels and positive mental health, with a stronger effect for the more active group who met the ACSM/AHA guidelines (Fernandes et al., 2009). Nevertheless, the low effect sizes obtained in the present study require some caution regarding the interpretation of a direct/unidirectional effect of physical activity on eudaimonic well-being. First, Besenski (2009) suggested that psychological well-being is best explained by the experience during health-enhancing physical activity, rather than its level (duration, frequency, intensity). Thus, experiencing eudaimonia during a physical activity (e.g., doing something you believe in, developing your potential, pursuing excellence, developing trusting interpersonal relations) is expected to be more strongly related with psychological well-being (Huta \& Ryan, 2010; Kimiecik, 2011), although hedonia might also be experienced (Waterman et al., 
2008). Second, our cross-sectional results cannot establish causality. Explicitly, physical activity may promote increments of some well-being dimensions, but individuals with higher well-being levels may also easily adopt health-promoting practices. Third, the low effect sizes and percentage of explained variance after adjusting for the sociodemographic variables, may also suggest that this association is mediated by other variables (e.g., fitness levels, self-efficacy, body satisfaction, self-esteem).

Within the positive health agenda, Ryff and Singer $(1998,2000)$ have suggested that people who fail to adhere to health behavioural practices may have a lack of meaningful life/work opportunities, personal development experiences, consistent relationships and social support, and feelings of meaningful life pursuits and environmental mastery. As such, individuals with a positive, purposive and meaningful life are likely to adopt or sustain practices of positive psychological functioning, such as taking care of one's physical, social and mental health. On the whole, our results provide preliminary empirical support for these assumptions, with differential patterns of associations between smoking, exercising and well-being measures. Therefore, the need for integrating key behavioural factors on positive health promotion policies and programs is of maximal importance. Thus, approaches to health promotion should not only emphasize the prevention and treatment of problem behaviours, but also the inclusion of the promotion of optimal health behaviours and sustaining supportive environments (Ryff \& Singer, 2000; Singer \& Ryff, 2001). However, future research should also clarify the nature of the relationship between healthpromoting behaviours and eudaimonic well-being.

\subsection{The effects of psychosocial factors}

Psychosocial factors were only measured by a single-item of body satisfaction. Despite this limitation, positive associations were found between this measure and all well-being dimensions, explaining $1 \%$ to $7 \%$ of additional variance after adjusting for sociodemographic and lifestyle factors. The highest correlations were obtained for selfacceptance, environmental mastery, positive relations with others and purpose in life. This evidence is in accordance with previous research that revealed stronger associations of global self-esteem with self-acceptance, purpose in life and environmental mastery (Compton, 2001; Paradise \& Kernis, 2002; Ryff, 1989).

Body satisfaction can be defined in terms of the thoughts and feelings about one's body image/appearance. It can be assessed as the difference between the perceived (current) and the ideal physical appearance (Damasceno et al., 2011), as the evaluation of one's body size, shape, muscularity, muscle tone and weight (Grogan, 2008), or as a specific domain of evaluation within a hierarchical multidimensional model of self-perceptions (e.g., Fox \& Corbin, 1989). Our results extend previous empirical evidence by showing that a specific domain of self-perceptions provides a basis for positive psychological functioning, even after controlling for sociodemographic and lifestyle factors.

Another associated point of extreme importance is the consistent relationship between physical activity and body satisfaction reported in the literature (Hausenblas \& Fallon, 2006) and also found in the present study $(r=0.15, p<0.001)$. Thus, body satisfaction may be a mediator variable between exercise and eudaimonic well-being, which is particularly important for women. Firstly, this mediation argument has been confirmed for the 
relationship between physical activity and subjective well-being (Rejeski et al., 2001). Secondly, a recent meta-analysis indicated that gender differences in self-esteem vary depending on the specific domain (Gentile et al., 2009). Results showed a male advantage in physical appearance self-esteem through all age periods which was most pronounced during adulthood. Therefore, we suggest that the environmental mastery and selfacceptance scores of women could be increased trough physical activity participation mediated by body satisfaction changes. Nevertheless, future research should focus on this type of interaction processes and related outcomes.

\subsection{Study limitations}

Some limitations should be considered regarding the obtained results. Firstly, although this community sample was randomly recruited from the northern and central regions of Portugal, it is not necessarily representative of the entire population, so additional caution is needed when generalizing from this data. Secondly, this is a cross-sectional study and, therefore, causal inferences should not be made.

\section{Conclusion}

In conclusion, the results of the present study allowed for the identification of factors associated with eudaimonic well-being. Sociodemographic (gender, age, place of residence, educational attainment and socioeconomic status), lifestyle (smoking and physical activity) and psychosocial (body satisfaction) variables exhibited different patterns of associations with positive mental health, as measured through Ryff's scales. Males, younger adults, urban residents and higher socioeconomic groups reported higher levels of well-being scores. Additionally, health behaviour practices (non-smoking and exercising) presented significant relations with some psychological well-being dimensions, underscoring the importance of the inclusion of key behavioural factors on positive health promotion policies and programs. Finally, body satisfaction exerted significant influences on all well-being scales and both direct and indirect effects on eudaimonic well-being were explored.

Overall, these results demonstrate that multiple factors (sociodemographic, lifestyle and psychosocial) are associated with positive mental health in a Portuguese community sample. Moreover, we expect that this evidence provides guidance to health sector reforms and other health policies focused on the creation and sustainment of supportive environments designed to promote positive mental health and well-being.

\section{References}

Almeida, D. \& Kessler, R. (1998). Everyday stressors and gender differences in daily distress. Journal of Personality and Social Psychology, Vol.75, pp. 670-680, ISSN 0022-3514

Antony, M. \& Swinson, R. (1996). Anxiety disorders: Future directions for research and treatment: A discussion paper. Health Canada/Minister of Supply and Services, ISBN 0-66224980-1 Ottawa, Ontario, Canada

Besenski, L. (2009). Health-enhancing physical activity and eudaimonic well-being. Master's thesis, University of Saskatchewan, Saskatoon, Canada

Caldas de Almeida, J. (2010). Estudo epidemiológico nacional de saúde mental. Faculdade de Ciências Médicas, Lisboa 
Campion, J.; Checinski, K.; Nurse, J. \& McNeill, A. (2008). Smoking by people with mental illness and benefits of smoke-free mental health services. Advances in Psychiatric Treatment, Vol.14, pp. 217-228, ISSN 1472-1481

Compton, W. (2001). Toward a tripartite factor structure of mental health: Subjective wellbeing, personal growth, and religiosity. The Journal of Psychology, Vol.135, No.5, pp. 486-500, ISSN 0022-3980

Compton, W.; Smith, M.; Cornish, K. \& Qualls, D. (1996). Factor structure of mental health measures. Journal of Personality and Social Psychology, Vol.71, No.2, pp. 406-413, ISSN 0022-3514

Damasceno, V.; Vianna, J.; Novaes, J.; Lima, J.; Fernandes, H. \& Reis, V. (2011). Relationship between anthropometric variables and body image dissatisfaction among fitness center users. Revista de Psicología del Deporte, Vol.20, No.2, pp. 367-382, ISSN 19885636

Davidson, R. (2004). Well-being and affective style: Neural substrates and biobehavioral correlates. Philosophical Transactions of the Royal Society of London B, Vol.359, pp. 1395-1411, ISSN 0080-4622

DeNeve, K. \& Cooper, H. (1998). The happy personality: A meta-analysis of 137 personality traits and subjective well-being. Psychological Bulletin, Vol.124, No.2, pp. 197-229, ISSN 0033-2909

DG SANCO (2007). Health in the European Union. Special Eurobarometer 272e/ Wave 66.2-TNS Opinion $\mathcal{E}$ Social. Office for Official Publications of the European Communities, Luxembourg

Diener, E. \& Diener, M. (1995). Cross-cultural correlates of life satisfaction and self-esteem. Journal of Personality and Social Psychology, Vol.69, No.1, pp. 120-129, ISSN 0022-3514

Diener, E. (2000). Subjective well-being: The science of happiness and a proposal for a national index. American Psychologist, Vol.55, No.1, pp. 34-43, ISSN 0003-066X

Diener, E.; Oishi, S. \& Lucas, R. (2003). Personality, culture, and subjective well-being: Emotional and cognitive evaluations of life. Annual Review of Psychology, Vol.54, pp. 403-425, ISSN 0066-4308

Diener, E.; Suh, E.; Lucas, R. \& Smith, H. (1999). Subjective well-being: Three decades of progress. Psychological Bulletin, Vol.125, No.2, pp. 276-302, ISSN 0033-2909

Edwards, S.; Ngcobo, H.; Edwards, D. \& Palavar, K. (2005). Exploring the relationship between physical activity, psychological well-being and physical self-perception in different exercise groups. South African Journal for Research in Sport, Physical Education E Recreation, Vol.27, pp. 75-90, ISSN 0379-9069

Fernandes, H. \& Vasconcelos-Raposo, J. (2008). O bem-estar psicológico em adolescentes: Uma abordagem centrada no florescimento humano. CEDAFES-UTAD, ISBN 978-972-669842-5, Vila Real, Portugal

Fernandes, H.; Vasconcelos-Raposo, J. \& Teixeira, C. (2010). Preliminary analysis of the psychometric properties of Ryff's Scales of Psychological Well-Being in Portuguese adolescents. The Spanish Journal of Psychology, Vol.13, No.2, pp. 1032-1043, ISSN $1138-7416$

Fernandes, H.; Vasconcelos-Raposo, J.; Pereira, E.; Ramalho, J. \& Oliveira, S. (2009). A influência da actividade física na saúde mental positiva de idosos. Motricidade, Vol.5, No.1, pp. 33-50, ISSN 1646-107X

Fitzgerald, P. \& Dinan T. (2010). Biological sex differences relevant to mental health, In: Oxford textbook of women and mental health, D. Kohen, (Ed.), 30-41, Oxford University Press, ISBN 978-0199214365, Oxford, Great Britan 
Fox, K. \& Corbin, C. (1989). The physical self-perception profile: Development and preliminary validation. Journal of Sport and Exercise Psychology, Vol.11, pp. 408-430, ISSN 0895-2779

Gentile, B.; Grabe, S.; Dolan-Pascoe, B.; Twenge, J.; Wells, B. \& Maitino, A. (2009). Gender differences in domain-specific self-esteem: A meta-analysis. Review of General Psychology, Vol.13, No.1, pp. 34-45, ISSN 1089-2680

Grant, N.; Wardle, J. \& Steptoe, A. (2009). The relationship between life satisfaction and health behavior: A cross-cultural analysis of young adults. International Journal of Behavioral Medicine, Vol.16, pp. 259-268, ISSN 1070-5503

Grogan, S. (2008). Body image: Understanding body dissatisfaction in men, women, and children (2nd ed.). Routledge, ISBN 978-041-5147-85-9, East Sussex, Great Britain

Gunnell, K. (2009). Leisure-time physical activity in individuals with osteoporosis: Associations with psychological well-being. Master's thesis, Brock University, Ontario, Canada

Hankin, B. \& Abramson, L. (2001). Development of gender differences in depression: An elaborated cognitive vulnerability-transactional stress theory. Psychological Bulletin, Vol.127, pp. 773-796, ISSN 0033-2909

Haskell, W.; Lee, I.; Pate, R.; Powell, K.; Blair, S.; Franklin, B.; Macera, C.; Heath, G.; Thompson, P. \& Bauman, A. (2007). Physical activity and public health: Updated recommendations for adults from the American College of Sports Medicine and the American Heart Association. Circulation, Vol.116, pp. 1081-1093, ISSN 0009-7322

Hausenblas, H. \& Fallon, E. (2006). Exercise and body image: A meta-analysis. Psychology and Health, Vol.21, pp. 33-47, ISSN 0887-0446

Heidrich, S. \& Ryff, C. (1993). Physical and mental health in later life: The self-system as mediator. Psychology and Aging, Vol.8, No.3, pp. 327-338, ISSN 0882-7974

Howell, R. \& Howell, C. (2008). The relation of economic status to subjective well-being in developing countries: A meta-analysis. Psychological Bulletin, Vol.134, No.4, pp. 536560, ISSN 0033-2909

Huta, V. \& Ryan, R. M. (2010). Pursuing pleasure or virtue: The differential and overlapping well-being benefits of hedonic and eudaimonic motives. Journal of Happiness Studies, Vol.11, pp. 735-762, ISSN 1389-4978

Kaplan, G.; Shema, S. \& Leite, C. (2008). Socioeconomic determinants of psychological wellbeing: The role of income, income change, and income sources during the course of 29 years. Annals of Epidemiology, Vol.18, No.7, pp. 531-537, ISSN 1047-2797

Keyes, C. (2005). Mental illness and/or mental health? Investigating axioms of the complete state model health. Journal of Consulting and Clinical Psychology, Vol.73, No.3, pp. 539-548, ISSN 0022-006X

Keyes, C.; Shmotkin, D. \& Ryff, C. (2002). Optimizing well-being: The empirical encounter of two traditions. Journal of Personality and Social Psychology, Vol.82, No.6, pp. 10071022, ISSN 0022-3514

Kimiecik, J. (2011). Exploring the promise of eudaimonic well-being within the practice of health promotion: The how is as important as the what. Journal of Happiness Studies, Vol.12, pp. 769-792, ISSN 1389-4978

Lawrence, D.; Mitrou, F. \& Zubrick, S. (2009). Smoking and mental illness: Results from population surveys in Australia and the United States. BMC Public Health, Vol.9, doi: 10.1186/1471-2458-9-285, ISSN 1471-2458

Lindfors, P. \& Lundberg, U. (2002). Is low cortisol release an indicator of positive health? Stress and Health, Vol.18, pp. 153-160, ISSN 1532-3005 
Linley, P.; Maltby, J.; Wood, A.; Osborne, G. \& Hurling, R. (2009). Measuring happiness: The higher order factor structure of subjective and psychological well-being measures. Personality and Individual Differences, Vol.47, pp. 878-884, ISSN 0191-8869

Marmot, M.; Ryff, C.; Bumpass, L.; Shipley, M. \& Marks, N. (1997). Social inequalities in health: next questions and converging evidence. Social Science and Medicine, Vol.44, No.6, pp. 901-910, ISSN 0277-9536

Mykletun, A.; Overland, S.; Aarø, L.; Liabø, H. \& Stewart, R. (2008). Smoking in relation to anxiety and depression: Evidence from a large population survey - the HUNT study. European Psychiatry, Vol.23, No.2, pp. 77-84, ISSN 0924-9338

Novo, R.; Duarte-Silva, E. \& Peralta, E. (1997). O bem-estar psicológico em adultos: Estudo das características psicométricas da versão portuguesa das escalas de C. Ryff. In: Avaliação psicológica: Formas e contextos, M. Gonçalves; I. Ribeiro; S. Araújo; C. Machado; L.S. Almeida \& M. Simões, (Ed.), vol. V, 313-324, APPORT/SHO, Braga, Portugal

Nurullah, A. (2010). Gender differences in distress: The mediating influence of life stressors and psychological resources. Asian Social Science, Vol.6, No.5, pp. 27-35, ISSN 1911-2017

Paradise, A. \& Kernis, M. (2002). Self-esteem and psychological well-being: Implications of fragile self-esteem. Journal of Social and Clinical Psychology, Vol.21, No.4, pp. 345-361, ISSN 0736-7236

Peen, J.; Dekker, J.; Schoevers, R.; Have, M.; de Graaf, R. \& Beekman, A. (2007). Is the prevalence of psychiatric disorders associated with urbanization? Social Psychiatry and Psychiatric Epidemiology, Vol.42, No.12, pp. 984-989, ISSN 0933-7954

Peen, J.; Schoevers, R.; Beekman, A. \& Dekker, J. (2010). The current status of urban-rural differences in psychiatric disorders. Acta Psychiatrica Scandinavica, Vol.121, No.2, pp. 84-93, ISSN 0001-690X

Rejeski, W.; Shelton, B.; Miller, M.; Dunn, A.; King, A. \& Sallis, J. (2001). Mediators of increased physical activity and change in subjective well-being: Results from the Activity Counseling Trial (ACT). Journal of Health Psychology, Vol.6, No.2, pp. 159168, ISSN 1359-1053

Rethorst, C.; Wipfli, B. \& Landers, D. (2009). The antidepressive effects of exercise: A metaanalysis of randomized trials. Sport Medicine, Vol.39, pp. 491-511, ISSN 0112-1642

Ryan, R. \& Deci, E. (2001). On happiness and human potentials: A review of research on hedonic and eudaimonic well-being. Annual Review of Psychology, Vol.52, pp. 141166, ISSN 0066-4308

Ryff, C. \& Heidrich, S. (1997). Experience and well-being: Explorations on domains of life and how they matter. International Journal of Behavioral Development, Vol.20, No.2, pp. 193-206, ISSN 0165-0254

Ryff, C. \& Singer, B. (1996). Psychological well-being: Meaning, measurement, and implications for psychotherapy research. Psychotherapy and Psychosomatics, Vol.65, pp. 14-23, ISSN 0033-3190

Ryff, C. \& Singer, B. (1998). The contours of positive human health. Psychological Inquiry, Vol.9, No.1, pp. 1-28, ISSN 1047-840X

Ryff, C. \& Singer, B. (2000). Interpersonal flourishing: A positive health agenda for the new millennium. Personality and Social Psychology Review, Vol.4, No.1, pp. 30-44, ISSN 1088-8683

Ryff, C. (1989). Happiness is everything, or is it? Explorations on the meaning of psychological well-being. Journal of Personality and Social Psychology, Vol.57, No.6, pp. 1069-1081, ISSN 0022-3514

Ryff, C.; Magee, W.; Kling, K. \& Wing, E. (1999). Forging macro-micro linkages in the study of psychological well-being. In: The self and society in aging processes, C. 
Ryff \& V. Marshall, (Ed.), 247-278, Springer, ISBN 978-0826112675, New York, USA

Ryff, C.; Singer, B. \& Love, G. (2004). Positive health: Connecting well-being with biology. Philosophical Transactions of the Royal Society B: Biological Sciences, Vol.359, pp. 13831394, ISSN 0962-8436

Scheier, M.; Carver, C. \& Bridges, M. (2001). Optimism, pessimism, and psychological wellbeing. In: Optimism and pessimism: Implications for theory, research, and practice, E. C. Chang, (Ed.), pp. 189-216, American Psychological Association, ISBN 9781557986917, Washington, DC, USA

Scott, D. \& Happell, B. (2011). The high prevalence of poor physical health and unhealthy lifestyle behaviours in individuals with severe mental illness. Issues in Mental Health Nursing, Vol.32, No.9, pp. 589-597, ISSN 0161-2840

Seligman, M. \& Csikszentmihalyi, M. (2000). Positive psychology: An introduction. American Psychologist, Vol.55, No.1, pp. 5-14, ISSN 0003-066X

Shahab, L., \& West, R. (2011). Differences in happiness between smokers, ex-smokers and never smokers: Cross-sectional findings from a national household survey. Drug and Alcohol Dependence, doi: 10.1016/j.drugalcdep.2011.08.011, ISSN 0376-8716

Singer, B. \& Ryff, C. (Eds.) (2001). New horizons in health: An integrative approach. National Academy Press, ISBN 978-0-309-07296-0, Washington, DC, USA

Spence, J.; McGannon, K. \& Poon, P. (2005). The effect of exercise on global self-esteem: A quantitative review. Journal of Sport E Exercise Psychology, Vol.27, No.3, pp. 311-334, ISSN 0895-2779

Springer, K.; Pudrovska, T. \& Hauser, R. (2011). Does psychological well- being change with age? Longitudinal tests of age variations and further exploration of the multidimensionality of Ryff's model of psychological well-being. Social Science Research, Vol.40, pp. 392-398, ISSN 0049-089X

Steel, P.; Schmidt, J. \& Shultz, J. (2008). Refining the relationship between personality and subjective well-being. Psychological Bulletin, Vol.134, No.1, pp. 138-161, ISSN 0033-2909

U.S. Department of Health and Human Services - USDHHS (2004). The health consequences of smoking: A report of the Surgeon General. USDHHS, CDCP, NCCDPHP, OSH, ISBN 016-051576-2, Atlanta, USA

Urry, H.; Nitschke, J.; Dolski, I.; Jackson, D.; Dalton, K.; Mueller, C.; Rosenkranz, M.; Ryff, C.; Singer, B. \& Davidson, R. (2004). Making a life worth living: Neural correlates of well-being. Psychological Science, Vol.15, No.6, pp. 367-372, ISSN 0956-7976

Vleioras, G. \& Bosma, H. A. (2005). Are identity styles important for psychological wellbeing? Journal of Adolescence, Vol.28, No.3, pp. 397-409, ISSN 0140-1971

Waterman, A., Schwartz, S. \& Conti, R. (2008). The implications of two conceptions of happiness (hedonic enjoyment and eudaimonia) for the understanding of intrinsic motivation. Journal of Happiness Studies, Vol.9, pp. 41-79, ISSN 1389-4978

WHO (2004). Gender in mental health research. World Health Organisation, ISBN 92-4-1592532, Geneva, Switzerland

WHO International Consortium in Psychiatric Epidemiology (2000). Cross-national comparisons of the prevalences and correlates of mental disorders. Bulletin of the World Health Organization, Vol.78, No.4, pp. 413-426, ISSN 0042-9686

Wilkening, E. \& McGranahan, D. (1978). Correlates of subjective well-being in Northern Wisconsin. Social Indicators Research, Vol.5, pp. 211-234, ISSN 0303-8300

Wipfli, B.; Rethorst, C. \& Landers, D. (2008). The anxiolytic effects of exercise: A metaanalysis of randomized trials and dose-response analysis. Journal of Sport E Exercise Psychology, Vol.30, pp. 392-410, ISSN 0895-2779 


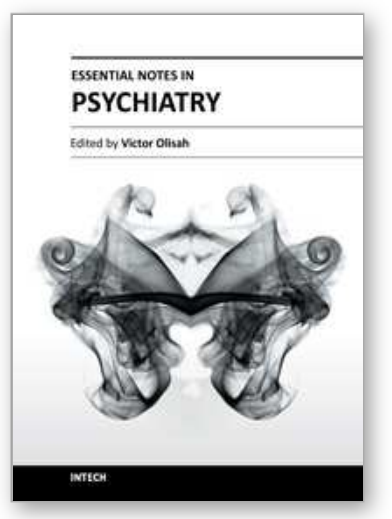

\author{
Essential Notes in Psychiatry \\ Edited by Dr. Victor Olisah
}

ISBN 978-953-51-0574-9

Hard cover, 580 pages

Publisher InTech

Published online 27, April, 2012

Published in print edition April, 2012

Psychiatry is one of the major specialties of medicine, and is concerned with the study and treatment of mental disorders. In recent times the field is growing with the discovery of effective therapies and interventions that alleviate suffering in people with mental disorders. This book of psychiatry is concise and clearly written so that it is usable for doctors in training, students and clinicians dealing with psychiatric illness in everyday practice. The book is a primer for those beginning to learn about emotional disorders and psychosocial consequences of severe physical and psychological trauma; and violence. Emphasis is placed on effective therapies and interventions for selected conditions such as dementia and suicide among others and the consequences of stress in the workplace. The book also highlights important causes of mental disorders in children.

\title{
How to reference
}

In order to correctly reference this scholarly work, feel free to copy and paste the following:

Helder Miguel Fernandes, José Vasconcelos-Raposo and Robert Brustad (2012). Factors Associated with Positive Mental Health in a Portuguese Community Sample: A Look Through the Lens of Ryff's Psychological Well-Being Model, Essential Notes in Psychiatry, Dr. Victor Olisah (Ed.), ISBN: 978-953-51-0574-9, InTech, Available from: http://www.intechopen.com/books/essential-notes-in-psychiatry/factors-associated-withpositive-mental-health-in-a-portuguese-community-sample-a-look-through-the

\section{INTECH}

open science | open minds

\author{
InTech Europe \\ University Campus STeP Ri \\ Slavka Krautzeka 83/A \\ 51000 Rijeka, Croatia \\ Phone: +385 (51) 770447 \\ Fax: +385 (51) 686166 \\ www.intechopen.com
}

\author{
InTech China \\ Unit 405, Office Block, Hotel Equatorial Shanghai \\ No.65, Yan An Road (West), Shanghai, 200040, China \\ 中国上海市延安西路65号上海国际贵都大饭店办公楼 405 单元 \\ Phone: +86-21-62489820 \\ Fax: $+86-21-62489821$
}


(C) 2012 The Author(s). Licensee IntechOpen. This is an open access article distributed under the terms of the Creative Commons Attribution 3.0 License, which permits unrestricted use, distribution, and reproduction in any medium, provided the original work is properly cited. 